\title{
Coronary artery bypass grafting in acute
} myocardial infarction: analysis of predictors of inhospital mortality

\author{
Cirurgia de revascularização miocárdica na fase aguda do infarto: análise dos fatores preditores de \\ mortalidade intra-hospitalar
}

Omar Asdrúbal Vilca Mejía ${ }^{1}$, Luiz A Ferreira Lisboa ${ }^{2}$, Marcos Gradim Tiveron ${ }^{3}$, José Augusto Duncan Santiago $^{4}$, Rafael Angelo Tineli ${ }^{5}$, Luis Alberto Oliveira Dallan ${ }^{6}$, Fabio Biscegli Jatene ${ }^{7}$, Noedir Antonio Groppo Stolf ${ }^{8}$

\section{Abstract}

Objective: Coronary artery bypass grafting (CABG) during the acute phase of infarction (AMI) is associated with increased operative risk. The aim of this study was to determine predictors of in-hospital mortality in patients undergoing CABG in AMI.

Methods: During three years, all patients undergoing CABG in AMI were retrospectively analyzed of the institutional database. Sixty variables per patient were evaluated: 49 preoperative variables from the 2000 Bernstein-Parsonnet and EuroSCORE models, 4 preoperative variables not considered in these models (time between AMI and CABG, maximum CKMB, Troponin maximum and ST-segment elevation) and 7 intraoperative variables [(cardiopulmonary bypass (CPB), CPB time, type of cardioplegia, endarterectomy, number of grafts, use of internal thoracic artery and complete revascularization].

1. Specialist in Aortic Surgery; Medical Residence in Cardiovascular Surgery at Heart Institution, Clinics Hospital of the Faculty of Medicine, University of São Paulo (InCor-HCFMUSP), São Paulo, SP, Brazil.

2. Full Professor at Faculty of Medicine, University of São Paulo (FMUSP); Assistant Physician at Surgical Coronaropathy Unit at InCor-HCFMUSP, São Paulo, SP, Brazil.

3. Specialist in Cardiovascular Surgery at FMUSP; Preceptor Physician of Cardiovascular Surgery Residence at FMUSP, São Paulo, SP, Brazil.

4. Specialist in General Surgery; Resident in Cardiovascular Surgery at InCor-HCFMUSP, São Paulo, SP, Brazil.

5. Specialist in Cardiovascular Surgery at FMUSP; Collaborator Physician at FMUSP, São Paulo, SP, Brazil.

6. Associate Professor at FMUSP; Head of the Surgical Coronaropathy at InCor-HCFMUSP, São Paulo, SP, Brazil.

7. Titular Professor of the Thoracic Surgery Discipline at FMUSP;
Univariate and multivariate analysis for the outcome of inhospital mortality were performed.

Results: The mean time between AMI and CABG was 3.8 \pm 3 days. The overall mortality was $19 \%$. In the multivariate analysis: age $>65$ years $\mathrm{OR}$ [16.5 (CI 1.8 to 152), $P=0.013$ ]; CPB > 108 minutes [OR 40 (CI 2.7 to 578), $P=0.007$ ], creatinine $>2 \mathrm{mg} / \mathrm{dl}$ [OR 35.5 (CI 1.7 to 740), $P=0.021]$ and systolic pulmonary pressure $>60 \mathrm{mmHg}$ [OR 31 (CI 1.6 to 591), $P=0.022]$ were predictors of in-hospital mortality.

Conclusion: Conventional preoperative variables such as age $>65$ years, creatinine $>2 \mathrm{mg} / \mathrm{dl}$ and systolic pulmonary pressure $>60 \mathrm{mmHg}$ were predictive of inhospital mortality in patients underwent CABG in AMI.

Descriptors: Risk factors. Myocardial infarction. Revascularização miocárdica. Coronary artery bypass.

Director of the Thoracic Surgery Service at InCor-HCFMUSP, São Paulo, SP, Brazil.

8. Titular Professor of the Cardiovascular Surgery Discipline at FMUSP, Director of the Surgical Division at InCor-HCFMUSP, São Paulo, SP, Brazil.

This study was carried out at Heart Institute, Clinics Hospital of the Faculty of Medicine, University of São Paulo, SP, Brazil.

Correspondence address:

Omar Asdrúbal Vilca Mejía

Av. Dr. Enéas Carvalho de Aguiar, 44 - Cerqueira César - São Paulo, SP, Brasil - CEP: 05403-000

E-mail: omarvilca@incor.usp.br 


\begin{tabular}{|ll|}
\hline Abbreviations, & Acronyms \& Symbols \\
\hline ACC & American College of Cardiology \\
AHA & American Heart Association \\
IAB & Intra-aortic balloon \\
CPB & Cardiopulmonar bypass \\
CKMB & creatine kinase MB isoenzyme \\
CABG & coronary artery bypass graft surgery \\
EuroSCORE & European System for Cardiac Operative Risk \\
& Evaluation \\
AMI & acute myocardial infarction \\
NSTEMI & NSTEMI acute myocardial infarction without \\
STEMI & ST-segment elevation \\
IQ & acute myocardial infarction with ST-segment \\
SPSS & elevation \\
& interquartile \\
& Statistical Package for Social Sciences \\
\hline
\end{tabular}

\section{Resumo}

Objetivo: A cirurgia de revascularização miocárdica (CRM) na fase aguda do infarto do miocárdio (IAM) está associada a aumento do risco operatório. $O$ objetivo do estudo foi determinar fatores preditores de mortalidade intrahospitalar nos pacientes submetidos a CRM no IAM.

Métodos: Durante três anos, todos os pacientes submetidos a CRM no IAM foram analisados retrospectivamente, utilizando o banco de dados institucional. Sessenta variáveis

\section{INTRODUCTION}

The high postoperative morbidity and high mortality rates of patients undergoing surgical revascularization for acute myocardial infarction led from the old to postpone the procedure. Even though the wait could worsen and increase infarct size with borderline irrigation, resulting in greater myocardial damage and ventricular remodeling [1], few studies have analyzed clinical and laboratory factors to determine that increased morbidity and mortality. Recent studies can demonstrate positive impact on survival with early revascularization [2], however this is still being delayed because of reports that describe mortality by $31 \%$ [3].

Therefore, there is no consensus about the risks and benefits of bypass surgery (CABG) for acute myocardial infarction (AMI), especially regarding the ideal time between diagnosis and surgery [4]. Although CABG is safe when performed electively, the effects caused by ischemic injury associated with other factors such as gender, age and other clinical data have not been fully reported [5]. por paciente foram avaliadas: 49 variáveis pré-operatórias provenientes dos escores 2000 Bernstein-Parsonnet e EuroSCORE; 4 variáveis pré-operatórias não consideradas por esses escores (tempo entre o IAM e a CRM, valor máximo de CKMB, valor máximo de troponina e supradesnivelamento do segmento ST) e 7 variáveis intraoperatórias [uso de circulação extracorpórea (CEC), tempo de CEC, tipo de cardioplegia, endarterectomia, número de enxertos, uso da artéria torácica interna e revascularização completa]. Análise univariada e multivariada para o desfecho mortalidade intrahospitalar foram realizadas.

Resultados: O tempo médio entre o IAM e a CRM foi de $3,8 \pm 3$ dias. A mortalidade global foi $19 \%$. Na análise multivariada: idade $>65$ anos $[O R$ 16,5 (IC 1,8-152), $P=0,013] \sim ~ C E C>108$ minutos [OR $40($ IC 2,7-578), $P=0,007]$, creatinina $>2 \mathrm{mg} / \mathrm{dl}$ [OR 35,5 (IC 1,7-740), $P=0,021]$ e pressão pulmonar sistólica > $60 \mathrm{mmHg}$ [OR 31(IC 1,6-591), $P=0,022]$ foram preditores de mortalidade intra-hospitalar.

Conclusão: Variáveis pré-operatórias clássicas como idade $>65$ anos, creatinina $>2 \mathrm{mg} / \mathrm{dl}$ e pressão pulmonar sistólica $>60 \mathrm{mmHg}$ foram preditoras de mortalidade intra-hospitalar nos pacientes operados de revascularização miocárdica na fase aguda do infarto.

Descritores: Fatores de risco. Infarto do miocárdio. Revascularização miocárdica. Ponte de artéria coronária.

The aim of this study was to elucidate what are the predictors of in-hospital mortality in patients undergoing CABG in AMI. To have a better scientific basis, most of the variables used in the study would have the same definitions of the EuroSCORE model [6] and 2000 Bernstein-Parsonnet [7], the same that have been validated for predicting inhospital mortality in the Heart Institute of University of São Paulo (São Paulo, SP, Brazil) [8].

\section{METHODS}

\section{Sample Size}

Between 2008 and 2010, 62 consecutive patients underwent CABG during the acute phase of AMI with either ST-segment elevation (NSTEMI) or without ST-segment elevation (NSTEMI) in the Heart Institute, Clinics Hospital, Faculty of Medicine at University of São Paulo.

\section{Criteria for inclusion and exclusion}

We included all patients who underwent $\mathrm{CABG}$ during the acute phase of AMI in the period defined. CABG during 
AMI has been shown in the following situations: (a) percutaneous coronary intervention unsuccessful or technically infeasible, (b) patient with frank hemodynamic instability or (c) patients with refractory persistent symptoms to drug treatment and/or intra-aortic balloon (IAB). The hospital records of patients were reviewed to determine pre-, intra- and postoperative data. Four patients were excluded from analysis due to missing data.

\section{Diagnostic and/or clinical criteria}

The MI was defined following the criteria of the World Health Organization, which determines the presence of necessary diagnostic criteria in three areas: clinical, electrocardiographic, and biochemical, within 7 days after the event. Electrocardiographic abnormalities were classified following the guidelines of the American Heart Association (AHA)/American College of Cardiology (ACC) and NSTEMI, when the ST segment is a convex or straight curve e" $1 \mathrm{~mm}$ in two or more contiguous leads, or NSTEMI, when there is ST segment depression e" $1 \mathrm{~mm}$, T wave inversion or normal on ECG. Considering the fact that patients are seen at varying times after the onset of ischemia, we analyzed the maximum value of the biomarkers of the $\mathrm{MB}$ isoenzyme of creatine kinase $(\mathrm{CK})$ and troponin $\mathrm{T}$, following the recommendations of the AHA / ACC to collect the samples in a sequence of $0,3,6$ and 12 hours, followed by serial determinations of each period of 6-8 hours. The time interval was given by the emergency records and calculated as the time between symptom onset and surgical intervention. The in-hospital mortality was defined as death between the procedure and hospital discharge.

\section{Surgical Technique}

After median sternotomy, patients underwent surgery with or without the use of cardiopulmonary bypass (CPB), the second option of the surgeon in charge. When operated using CPB, CABG was performed in normothermia or mild hypothermia and arterial cannulation was performed in the ascending aorta and venous in the right atrium. Myocardial protection was induced by blood or crystalloid cardioplegia using the antegrade route. In patients operated without $\mathrm{CPB}$ it was used regional cardiac stabilizer.

\section{Statistical Analysis}

Sixty variables per patient were analyzed: 49 preoperative scores from the 2000 Bernstein-Parsonnet and EuroSCORE, 4 preoperative variables not considered in the scores (time between the onset of AMI and CABG, maximum CKMB, peak troponin and ST-segment elevation) and 7 intraoperative variables (CPB, CPB time, type of cardioplegia, presence of carotid endarterectomy, grafts, use of internal thoracic artery and the presence of complete revascularization). All data were transformed into values of
EuroSCORE and Parsonnet-Bernstein 2000, following the definitions given by both scores [9.11].

Data for categorical variables were expressed through their frequencies and percentages and continuous variables as means and their standard deviation or median and interquartile range $25-75 \%$ (IQ25-75\%) when the variable is not normally distributed. Differences in categorical variables were analyzed using the chi-square or Fisher exact, when the expected values were less than five, the differences between continuous variables were analyzed by independent Student $\mathrm{t}$ test or Mann-Whitney test when the variable is not normally distributed. The odds ratio (odds ratio) was used for the weighting of the risk posed by each categorized variable. In order to consider the difference of means, frequencies or the presence of correlation between variables was used the statistical significance value less than or equal to $5 \%$ ( $\mathrm{p} \mathrm{d}$ " 0.05 ).

Multivariate logistic regression (forward stepwise) of pre- and intraoperative variables was performed to identify predictors of in-hospital mortality. The modeling and statistical tests were performed using the Statistical Package for Social Sciences (SPSS) version 13.0 (SPSS Inc., Chicago, IL, USA).

\section{Ethics and consent}

This study was approved by the Ethics Committee for Analysis of Research Projects of the Clinics Hospital of the University of São Paulo under the number 1575, which exempted the need for the written informed consent because it was a retrospective study. There was no conflict of interest of authors in this study.

\section{RESULTS}

The demographic and clinical characteristics of patients are summarized in Table 1 (A, B and C). The rate of inhospital mortality was $19 \%$ ( 11 of 58 patients). Of the deaths, $80 \%$ were operated using CPB, of whom two patients had a diagnosis of VSD after AMI. Complete revascularization was achieved in $57 \%$ (33 patients) with a mean of $2.8 \pm 0.9$ grafts per patient. The left internal thoracic artery was used in all patients. Coronary thromboendarterectomy was performed in one patient. The mean duration of CPB was $104 \pm 34$ minutes. Postoperatively, 20 (34.5\%) patients required IABP. The stay in the intensive care unit was $10 \pm$ 13 days and the duration of mechanical ventilation, $80 \pm$ 149 hours. Hemodialysis was initiated in $5.2 \%$ of patients.

\section{Analysis of risk factors}

In the univariate analysis (Table 2), the risk factors related to in-hospital mortality were severe congestive heart failure, advanced age, VSD after AMI, cardiogenic shock, CPB, pulmonary hypertension and increased creatinine. The 
Table 1. A. Preoperative characteristics included in the EuroSCORE and Parsonnet-Bernstein in 2000 for deaths and survivors

\begin{tabular}{|c|c|c|c|}
\hline Preoperative characteristics & Deaths (11) & Survivors (47) & $P$ \\
\hline Age & $69.7 \pm 13.3$ & $63.7 \pm 13.3$ & 0.176 \\
\hline Female gender & $45 \%$ & $27.7 \%$ & 0.290 \\
\hline Congestive failure & $90 \%$ & $51.1 \%$ & 0.019 \\
\hline Severe COPD & $0 \%$ & $0 \%$ & \\
\hline Diabetes & $45.5 \%$ & $42.6 \%$ & 1.000 \\
\hline LCT > $>50 \%$ & $36.4 \%$ & $29.8 \%$ & 0.724 \\
\hline $\mathrm{EF}<30 \%$ & $27.3 \%$ & $17.0 \%$ & 0.421 \\
\hline Arterial hypertension & $90.9 \%$ & $87.2 \%$ & 1.000 \\
\hline Morbid obesity & $9.1 \%$ & $6.4 \%$ & 1.000 \\
\hline Preoperative IBA & $63.6 \%$ & $76.6 \%$ & 0.450 \\
\hline Reoperation & - & - & \\
\hline Treatment of aortic valve & - & - & \\
\hline Treatment of mitral valve & - & - & \\
\hline Valve treatment and $\mathrm{CABG}$ & - & - & \\
\hline Cardiogenic shock & $27.3 \%$ & $2 \%$ & 0.019 \\
\hline Acute endocarditis & - & - & \\
\hline Treated endocarditis & - & - & \\
\hline LV aneurysmectomy & - & - & \\
\hline Treatment of tricuspid valve & - & - & \\
\hline Pacemaler dependant & $9.1 \%$ & $4.3 \%$ & 0.474 \\
\hline AMI $48 \mathrm{~h}$ & $100 \%$ & $100 \%$ & \\
\hline Post-IVC AMI & $18.2 \%$ & $0 \%$ & 0.033 \\
\hline Ventricular tachycardia & $0 \%$ & $2.1 \%$ & 1.000 \\
\hline Asthma & - & - & \\
\hline Preoperative Oi & $9.1 \%$ & $6.4 \%$ & 1.000 \\
\hline Pulmonary hypertension & $36.4 \%$ & $4.3 \%$ & 0.009 \\
\hline Purpura thrombocytopenic & $9.1 \%$ & $0 \%$ & 0.190 \\
\hline Cirrhosis & $0 \%$ & $0 \%$ & \\
\hline Dialysis dependant & $9.1 \%$ & $2.1 \%$ & 0.346 \\
\hline Acute/chronic renal failure & $18.2 \%$ & $0 \%$ & 0.033 \\
\hline Preoperative serum creatinine & 1.49(IQ 1.22-2.34) & 1.01 (IQ $0.87-1.26$ ) & 0.011 \\
\hline Presence of aortic aneurysm & $0 \%$ & $0 \%$ & \\
\hline Carotid artery disease $>70 \%$ & $0 \%$ & $0 \%$ & \\
\hline Peripheral vascular disease & $0 \%$ & $6.4 \%$ & 1.000 \\
\hline Reaction to blood products & $0 \%$ & $2.1 \%$ & 1.000 \\
\hline Neurologic dysfunction & $0 \%$ & $0 \%$ & \\
\hline Prior percutaneous intervention & $45.5 \%)$ & $19.1 \%$ & 0.112 \\
\hline Severe smoking & $9.1 \%$ & $21.3 \%$ & 0.671 \\
\hline Serum creatinine $>200 \mu \mathrm{mol} / \mathrm{L}$ & $27.3 \%$ & $2.1 \%$ & 0.019 \\
\hline Preoperative inotropic support & $36.4 \%$ & $12.8 \%$ & 0.083 \\
\hline Preoperative massage & $0 \%$ & $0 \%$ & \\
\hline Unstable angina & $54.5 \%$ & $80.9 \%$ & 0.112 \\
\hline Recent myocardial infarction ( $<90$ days) & $11(100 \%)$ & $47(100 \%)$ & 1.000 \\
\hline Emergency surgery & $36.4 \%$ & $27.7 \%$ & 0.715 \\
\hline Early aortic intervention & $9.1 \%$ & $4.3 \%$ & 0.474 \\
\hline Surgery including thoracic aorta & $0 \%$ & $0 \%$ & \\
\hline Atrial fibrillation & $0 \%$ & $0 \%$ & \\
\hline Left atrial size & $46 \mathrm{IQ}(42-52)$ & 41 IQ $(39.75-44)$ & 0.021 \\
\hline Dyslipidemia & $72.7 \%$ & $40.4 \%$ & 0.091 \\
\hline Additive EuroSCORE & $12.1 \pm 3.2$ & $8.3 \pm 3.5$ & 0.002 \\
\hline 2000Bernstein-Parsonnet & $39.6 \pm 9.7$ & $22.6 \pm 9.9$ & $<0.001$ \\
\hline
\end{tabular}

CABGwith/AMI: Myocardial revascularization in acute myocardial infarction; CABGwithtout/AMI: Myocardial revascularization without acute myocardial infarction, COPD: Chronic obstructive pulmonary disease; $L C T=$ Trunk of left coronary artery; EF : ejection fraction; IAB = Intra-aortic balloon, post-IVC AMI = interventricular communication after acute myocardial infarction; Oi: orotracheal intubation 
Table 1. B. Preoperative characteristics not included in the EuroSCORE and Parsonnet-Bernstein in 2000.

\begin{tabular}{lccr}
\hline Preoperative characteristics & Deaths (11) & Survivors $(47)$ & $P$ \\
\hline Dt: AMI-CABG & 3 (IQ 1 - 9) & 3 (IQ 2 - 5) & 0.928 \\
Maximum value of CKMB & 9 (IQ 7.31 - 31.5) & 19.6 (IQ 8.2 - 70) & 0.194 \\
Maximum value of troponin & 27 (IQ 4.92-46.7) & 8.2 (IQ 2 - 26) & 0.208 \\
ST & $54.56 \%$ & $23.4 \%$ & 0.064 \\
\hline
\end{tabular}

$D t=$ Time between the acute myocardial infarction and coronary artery bypass surgery, $C K-M B=M B$ isoenzyme of creatine kinase; SupraST = ST-segment elevation

Table 1. C. Intraoperative characteristics.

\begin{tabular}{lccc}
\hline Intraoperative characteristics & Deaths (11) & Survivors (47) & $P$ \\
\hline CPB use & $91 \%$ & $85.1 \%$ & 1.000 \\
CPB time & $125.3 \pm 45.1$ & $100.2 \pm 27.7$ & 0.122 \\
Cardioplegia time & $81.8 \%$ & $78.3 \%$ & 1.000 \\
Thromboendarterectomy & $0 \%$ & $2.2 \%$ & 1.000 \\
Number of grafts & 3.0 (IQ $2.0-3.0)$ & 3.0 (IQ $2.0-3.0)$ & 0.759 \\
Use of internal thoracic artery & $100 \%$ & $95.7 \%$ & 1.000 \\
Full revascularization (by injuried artery) & $54.5 \%$ & $57.4 \%$ & 1.000 \\
\hline
\end{tabular}

$C P B=$ cardiopulmonary bypass

Table 2. Univariate analysis.

\begin{tabular}{|c|c|c|c|c|}
\hline Variable & OR & & $\mathrm{I}$ & $P$ \\
\hline Gender & 0.46 & 0.12 & 1.77 & 0.290 \\
\hline Congestive failure & 9.59 & 1.14 & 80.95 & 0.02 \\
\hline Age & 4.3 & 1.01 & 18.34 & 0.05 \\
\hline Diabetes & 1.13 & 0.3 & 4.21 & 1.000 \\
\hline Morbid obesity & 1.47 & 0.14 & 15.61 & 1.000 \\
\hline Preoperative IAB & 0.54 & 0.13 & 2.17 & 0.45 \\
\hline $\mathrm{LCT}$ & 1.35 & 0.39 & 5.35 & 0.72 \\
\hline Pacemaker dependant & 2.25 & 0.19 & 27.31 & 0.474 \\
\hline post-IVC AMI & 6.22 & 3.42 & 11.32 & 0.033 \\
\hline Cardiogenic shock & 17.25 & 1.59 & 187.22 & 0.019 \\
\hline Ventricular tachycardia & 1.24 & 1.09 & 1.41 & 1.000 \\
\hline Vascular disease & 1.25 & 1.1 & 1.43 & 1.000 \\
\hline Reaction to blood products & 1.24 & 1.09 & 1.41 & 1.000 \\
\hline $\mathrm{Dt}<4$ days & 1.131 & 0.26 & 4.91 & 1.000 \\
\hline Dialysis & 4.60 & 0.27 & 79.92 & 0.346 \\
\hline CKMB & 0.39 & 0.09 & 1.66 & 0.314 \\
\hline Troponin & 2.05 & 0.23 & 18.36 & 1.000 \\
\hline ST & 3.93 & 1.01 & 15.3 & 0.064 \\
\hline $\mathrm{CPB}$ & 5.10 & 1.27 & 20.54 & 0.029 \\
\hline Prior PTCA & 3.52 & 0.86 & 14.15 & 0.112 \\
\hline Inotropic support & 3.91 & 0.87 & 17.46 & 0.083 \\
\hline Unstable angina & 0.28 & 0.07 & 1.14 & 0.112 \\
\hline Postoperative AMI & 1.39 & 0.31 & 6.22 & 0.696 \\
\hline Blood cardioplegia & 1.25 & 0.23 & 6.739 & 1.000 \\
\hline Left mammary & 0.80 & 0.71 & 0.92 & 1.000 \\
\hline DLP & 3.93 & 0.92 & 16.74 & 0.091 \\
\hline Full revascularization & 0.89 & 0.24 & 3.33 & 1.000 \\
\hline Ejection fraction $<30$ & 1.83 & 0.4 & 8.44 & 0.421 \\
\hline Systolic pulmonary pressure $>60 \mathrm{mmHg}$ & 12.86 & 1.98 & 83.83 & 0.009 \\
\hline Creatinine $>2 \mathrm{mg} / \mathrm{dl}$ & 17.25 & 1.6 & 187.22 & 0.019 \\
\hline
\end{tabular}

$I A B=$ intra-aortic balloon; $L P T=$ Trunk of left coronary artery; post-IVCAMI = interventricular communication after acute myocardial infarction; $D t=$ time between $A M I$ and $C A B G, C K-M B=M B$ isoenzyme of creatine kinase; Supra $S T=S T$-segment elevation $; C P B=$ cardiopulmonary bypass; prior $P T C A=$ percutaneous intervention prior; $D L P=$ Dyslipidemia 
Table 3. Predictor variables from the multivariate analysis.

\begin{tabular}{lcccc}
\hline Variable & OR & \multicolumn{2}{c}{ CI } & $P$ \\
\hline Age $>65$ years & 16.50 & 1.8 & 152 & 0.013 \\
Creatinine $>2 \mathrm{mg} / \mathrm{dl}$ & 35.45 & 1.7 & 740 & 0.021 \\
Systolic pulmonary pressure $>60 \mathrm{mmHg}$ & 30.98 & 1.62 & 591.05 & 0.022 \\
CPB $>107$ minutes & 39.7 & 2.79 & 577.71 & 0.007 \\
Constant & -5.86 & & & $<0001$ \\
\hline
\end{tabular}

$C P B=$ cardiopulmonary bypass

mean EuroSCORE $(12.1 \pm 3.2)$ and the 2000 BernsteinParsonnet $(40 \pm 9.7)$ and deaths in relation to mean EuroSCORE (8.2 \pm 3.5$)$ and the 2000 Bernstein- Parsonnet $(23 \pm 10)$ in survivors, showed statistical difference $(P<0.05)$ for both scores. The incidence of death in patients who received stent prior to surgery was $37 \%(5 / 14)$ and who had severe lesions of the left main coronary artery, 20\% (4/ 20). Among the intraoperative variables, the increase in the time of CPB was the only significant variable in univariate analysis. Among the postoperative factors, the prolonged stay in intensive care unit, ventilation time and the need for hemodialysis were not significant predictors of in-hospital mortality in univariate analysis (Table 2).

In multivariate analysis, preoperative variables, age> 65 years, creatinine $>2 \mathrm{mg} / \mathrm{dL}$ and systolic pulmonary pressure $>60 \mathrm{mmHg}$ were predictive of in-hospital mortality (Table 3). On the other hand, CPB> 108 minutes was not the only preoperative variable predictive of in-hospital mortality. Although the in-hospital mortality was higher among patients with NSTEMI compared to NSTEMI, there was no statistically significant difference. Ejection fraction $<30$ was not predictor of in-hospital mortality in patients with AMI. The time between symptom onset and surgery was divided into three groups: $<4$ days, 4 to 6 days and $>6$ days. For the sample period $<4$ days had the worst prognosis, followed by the period $>6$ days and improvement in patients operated on between the 4th and 6th days, although not statistically significant. Likewise, there was no statistical significance in relation to enzyme markers CKMB and troponin $\mathrm{T}$.

\section{DISCUSSION}

In recent years, the mortality benefit with early and late invasive treatment strategies in patients with acute coronary syndrome has been clearly demonstrated. In these studies, the majority of procedures performed during the acute phase of AMI were the percutaneous intervention.
Regarding surgery as primary option, the poor results in the 70 s (> 20\% mortality) postponed the indication for 30 days after infarction [9]. However, actual results of the CABG can not be compared to those obtained in the 70s. Studies that compare current strategies for this invasive reperfusion with conservative medical management group note that the invasive (surgical or percutaneous) presents a shorter hospital stay, less re-hospitalization frequency, lower incidence of nonfatal reinfarction and lower mortality [10, 11]. Otherwise, we will have a greater chance of reinfarction, due to lingering injuries, and expansion of the infarcted area, with consequent ventricular remodeling and greater likelihood of aneurysm formation.

This new tendency responds to better understand of the results and the selection of patients, progress of CPB and myocardial protection, greater use of arterial grafts, and use of IABP and mechanical circulatory support, improvement of postoperative care and the benefits of surgery without cardiopulmonary bypass.

Jatene et al. [12] published in 2001, one of the earliest studies in Brazil related to CABG in AMI, where 49 patients were divided into two groups: group I without complications and group II with complications (recurrent ischemia, congestive heart failure, cardiogenic shock, hypotension, reinfarction, sustained ventricular tachycardia and ventricular fibrillation). Patients with mechanical complications were excluded. Mortality occurred only in Group II (15\%), with an average of 12 days from the onset of AMI and CRM. In our analysis, 10 years later and in a group that, besides the clinical characteristics of group II, includes mechanical complications, there was a mortality of $19 \%$, with an average of 72 hours between the onset of $\mathrm{AMI}$ and $\mathrm{CABG}$.

The analytic epidemiology reveals that approximately $10 \%$ of patients with MI had the same inclusion criteria as patients in our sample and that when undergoing $\mathrm{CABG}$ had a mortality rate of approximately $26 \%$ [13].

With regard to time of intervention, we found that the 
CABG between the fourth and sixth day had the lowest mortality but without statistical significance. Several authors have been concerned with the optimal time of surgery. An analysis of 32,099 patients undergone surgery after AMI in the state of New York (USA) between 1991 and 1996 showed that mortality decreased with increasing time interval between AMI and CABG. On the third day, the mortality curve showed an inflection, after which the levels of mortality are similar to those of elective surgery. The conclusion of this study was that, whenever possible (considering the clinical conditions), surgery should be postponed the first three days after AMI [14]. These trends have resulted in decreased length of stay, angina time, recurrent AMI, hospital infection and decreased mortality [15]. In our analysis, a larger sample might have defined in favor of what is currently accepted.

One important aspect relates to the inclusion of appropriate variables for the type of population. In our opinion, preoperative variables, such as type of infarction, time between AMI and CABG, time to angina, levels of enzyme markers and critical preoperative state, are not specified by the scores used. The EuroSCORE adequately determines the mortality rate for groups of medium and low risk but in high-risk group it is needed subgroups that have not yet been established [6.16]. Thus, for example, there is evidence that the failure to percutaneous intervention during the AMI increases the risk of mortality, which is considered the model of the 2000 Bernstein-Parsonnet, but not by the EuroSCORE and the majority of existing risk models.

In our analysis, the mean EuroSCORE value was $>9$ and the 2000 Bernstein-Parsonnet $>25$, both describing a very high risk patients and showed a direct relationship between the score and mortality. The high surgical morbidity and mortality that may accompany this group of patients is a reflection of poor preoperative clinical condition [8], expressed by the high prevalence of specific predictive factors. Inside the variables, some of which had statistical significance in our analysis are reported in the literature as important. Age > 65 years had a significant relationship with mortality and this relationship was reported by Applebaum et al. [17] and Kaul et al. [18] in patients aged over 70 years of age. The female gender has been suggested by some authors, among them Kaul et al. [18], as a predictor of hospital mortality after CABG in AMI. Although in our analysis this correlation has not been established, other authors such as Applebaum et al. [17] and Naunheim et al. [19] also found no association between female gender and early mortality.

Lee et al. [20] in a multicenter study involving 44,365 patients, found higher mortality in the group with NSTEMI compared to STEMI,only when they underwent surgery in the first week after AMI. Other authors note that the surgery within the first three days after infarction is a predictor of mortality, especially in STEMI. Furthermore, patients with NSTEMI require more than IBA and vasoactive drugs $[9,10]$. In this study, we found no statistical difference between these groups.

The preoperative clinical conditions determine significantly different changes in the postoperative period and the relationship of greater importance in predicting the risk. In general, there are two groups, patients with AMI without clinical complications and patients with AMI who present with complications of any kind, including mechanical damage or heart failure. Clinically stable patients present $1.4 \%$ mortality after CABG, compared with $12.5 \%$ in patients with a clinical complication preoperatively [12].

Some groups show that the left internal thoracic artery was $50 \%$ less used to irrigate the territory of the left anterior descending artery surgery in less than 48 hours after AMI. The same studies indicate that only those arteries that caused ischemia should be revascularized, and the number of grafts reduced to a minimum. Thus, it is reduced surgical time, and therefore the incidence of complications [9]. In the sample, the internal thoracic artery was used in all patients. We had a rate of complete revascularization in $58 \%$ of patients, this using the concept of a diseased artery revascularization [21], reaching $85 \%$ when used the definition by the myocardial wall.

The presence of cardiogenic shock increased mortality rate up to $59 \%$ in emergency $\mathrm{CABG}$ and, when the coronary blood flow was not reversed, the mortality rate can reach $78 \%$ [22]. In our group, patients with AMI and cardiogenic shock who underwent surgery presented mortality rate that reached $75 \%$. Likewise, there are reports describing that in critically ill patients, the $\mathrm{CABG}$ without $\mathrm{CPB}$ decreases the rate of in-hospital mortality relative to $\mathrm{CABG}$ with $\mathrm{CPB}$, mainly by decreasing the surgical time (incomplete revascularization) [23]. Although CPB time exceeding 108 minutes was the only preoperative variable that was not predictive of mortality, it was not considered. The reason is due to the fact that in the on-pump group, there were patients with post-AMI IVC and no analysis (at least univariate) comparing the mortality of patients undergone surgery with $\mathrm{CPB}$ with those patients on whom CPB was not performed.

In the sample there was no relation of mortality to the levels of troponin and CK-MB, similar to what was found by Hagl et al. [24], reporting that the maximum values of marker enzymes of myocardial necrosis had no impact on survival.

There are studies that conclude that antegrade/ retrograde blood cardioplegia is superior to crystalloid cardioplegia in CABG after AMI [25]. In the sample, although not statistically significant, $81 \%$ of deaths undergone surgery using crystalloid cardioplegia, supporting this hypothesis. 
Limitations of this study relate to its retrospective design and the fact that it was performed in a single center. Although most publications on the subject are based on small samples, multicenter, randomized studies should answer about the costs and benefits of CABG in AMI.

\section{CONCLUSION}

Preoperative classic variables, such as age $>65$ years, creatinine $>2 \mathrm{mg} / \mathrm{dL}$ and systolic pulmonary pressure $>60$ $\mathrm{mmHg}$, were important in predicting in-hospital mortality of patients undergoing CABG in the acute phase of AMI.

\section{REFERENCES}

1. Sintek CF, Pfeffer TA, Khonsari S. Surgical revascularization after acute myocardial infarction. Does timing make a difference? J Thorac Cardiovasc Surg. 1994;107(5):1317-21.

2. Van de Werf F, Ardissino D, Betriu A, Cokkinos DV, Falk E, Fox KA, et al; Task Force on the Management of Acute Myocardial Infarction of the European Society of Cardiology. Management of acute myocardial infarction in patients presenting with ST-segment elevation. The task force on the Management of Acute Myocardial Infarction of the European Society of Cardiology. Eur Heart J. 2003;24(1):28-66.

3. Eagle KA, Guyton RA, Davidoff R, Edwards FH, Ewy GA, Gardner TJ, et al; American College of Cardiology; American Heart Association. ACC/AHA 2004 guideline update for coronary artery bypass graft surgery: a report of the American College of Cardiology/American Heart Association Task Force on Practice Guidelines (Committee to Update the 1999 Guidelines for Coronary Artery Bypass Graft Surgery). Circulation. 2004;110(14):e340-437.

4. Deeik RK, Schmitt TM, Ihrig TG, Sugimoto JT. Appropriate timing of elective coronary artery bypass graft surgery following acute myocardial infarction. Am J Surg. 1998;176(6):581-5.

5. Zaroff JG, diTommaso DG, Barron HV. A risk model derived from the National Registry of Myocardial Infarction 2 database for predicting mortality after coronary artery bypass grafting during acute myocardial infarction. Am J Cardiol. 2002;90(1):1-4.

6. Nashef SA, Roques F, Michel P, Gauducheau E, Lemeshow S, Salamon R. European system for cardiac operative risk evaluation (EuroSCORE). Eur J Cardiothorac Surg. 1999;16(1):9-13.

7. Bernstein AD, Parsonnet V. Bedside estimation of risk as an aid for decision-making in cardiac surgery. Ann Thorac Surg. 2000;69(3):823-8.

8. Mejía OA, Lisboa LA, Puig LB, Dias RR, Dallan LA, Pomerantzeff PM, et al. The 2000 Bernstein-Parsonnet score and EuroSCORE are similar in predicting mortality at the Heart Institute, USP. Rev Bras Cir Cardiovasc. 2011;26(1):1-6.

9. Braxton JH, Hammond GL, Letsou GV, Franco KL, Kopf GS Elefteriades JA, et al. Optimal timing of coronary artery bypass graft surgery after acute myocardial infarction. Circulation. 1995;92(9 Suppl):II66-8.

10. Raghavan R, Benzaquen BS, Rudski L. Timing of bypass surgery in stable patients after acute myocardial infarction. Can J Cardiol. 2007;23(12):976-82.

11. Alter DA, Tu JV, Autsin PC, Naylor CD. Waiting times, revascularization modality, and outcomes after acute myocardial infarction at hospitals with and without on-site revascularizations facilities in Canada. J Am Coll Cardiol. 2003;42(3):410-9.

12. Jatene FB, Nicolau JC, Hueb AC, Atik FA, Barafiole LM, Murta $\mathrm{CB}$, et al. Fatores prognósticos da revascularização na fase aguda do infarto agudo do miocárdio. Rev Bras Cir Cardiovasc. 2001;16(3):195-202.

13. Yavuz S. Surgery as early revascularization after acute myocardial infarction. Anadolu Kardiyol Derg. 2008;8(Suppl 2):84-92.

14. Lee DC, Oz MC, Weinberg AD, Ting W. Appropriate timing of surgical intervention after transmural acute myocardial infarction. J Thorac Cardiovasc Surg. 2003;125(1):115-9.

15. Mohr R, Moshkovitch Y, Shapira I, Amir G, Hod H, Gurevitch J. Coronary artery bypass without cardiopulmonary bypass for patients with acute myocardial infarction. $\mathbf{J}$ Thorac Cardiovasc Surg. 1999;118(1):50-6.

16. Nashef SA, Roques F, Hammill BG, Peterson ED, Michel P, Grover FL, et al; EurpSCORE Project Group. Validation of European System for Cardiac Operative Risk Evaluation (EuroSCORE) in North American cardiac surgery. Eur J Cardiothorac Surg. 2002;22(1):101-5.

17. Applebaum R, House R, Rademaker A, Garibaldi A, Davis Z, Guillory $\mathrm{J}$, et al. Coronary artery bypass grafting within thirty 
days of acute myocardial infarction. Early and late results in 406 patients. J Thorac Cardiovasc Surg. 1991;102(5):745-52.

18. Kaul TK, Fields BL, Riggins SL, Dacumos GC, Wyatt DA, Jones CR. Coronary artery bypass grafting within 30 days of an acute myocardial infarction. Ann Thorac Surg. 1995;59(5):1169-76.

19. Naunheim KS, Kesler KA, Kanter KR, Fiore AC, McBride LR, Pennington DG, et al. Coronary artery bypass for recent infarction. Predictors of mortality. Circulation. 1988;78(3 Pt 2):I122-8.

20. Lee DC, Oz MC, Weinberg AD, Lin SX, Ting W. Optimal timing of revascularization: transmural versus nontransmural acute myocardial infarction. Ann Thorac Surg. 2001;71(4):1197-202.

21. Sergeant P, Blackstone E, Meyns B, Stockman B, Jashari R. First cardiological or cardiosurgical reintervention for ischemic heart disease after primary coronary artery bypass grafting. Eur J Cardiothorac Surg. 1998;14(5):480-7.
22. Hochman JS, Sleeper LA, Webb JG, Sanborn TA, White HD, Talley JD, et al. Early revascularization in acute myocardial infarction complicated by cardiogenic shock. SHOCK Investigators. Should We Emergently Revascularize Occluded Coronaries for Cardiogenic Shock. N Engl J Med. 1999;341(9):625-34.

23. Rastan AJ, Eckenstein JI, Hentschel B, Funkat AK, Gummert $\mathrm{JF}$, Doll N, et al. Emergency coronary artery bypass graft surgery for acute coronary syndrome: beating heart versus conventional cardioplegic cardiac arrest strategies. Circulation. 2006;114(1 Suppl):I477- 85.

24. Hagl C, Khaladj N, Peterss S, Martens A, Kutschka I, Goerler $\mathrm{H}$, et al. Acute treatment of ST-segment-elevation myocardial infarction: is there a role for the cardiac surgeon? Ann Thorac Surg. 2009;88(6):1786-92.

25. Pichon H, Chocron S, Alwan K, Toubin G, Kaili D, Falcoz P, et al. Crystalloid versus cold blood cardioplegia and cardiac troponin I release. Circulation. 1997;96(1):316-20. 